УДК 929:62(47)(045)

\title{
E.В. Тронина
}

\section{НЕКОТОРЫЕ АСПЕКТЫ МИРОВОЗЗРЕНИЯ С. Н. ВАНКОВА (ПО МАТЕРИАЛАМ ЕГО ВОСПОМИНАНИЙ)}

\begin{abstract}
В статье на основе воспоминаний С. Н. Ванкова рассматриваются его мировоззрение и жизненное кредо: выявляются мотивы профессиональной и общественной деятельности, отношение к труду, восприятие Родины, власти и общества. На протяжении всей его жизни прослеживается неизменность его жизненных принципов и убеждений независимо от смены в России политической власти. Вопросы мировоззрения представителей инженерно-технической интеллигенции конца XIX — первой трети XX вB., к ярким представителям которой относится Семён Николаевич Ванков, приобретают особую актуальность в связи с сотрудничеством прежде буржуазных специалистов с советской властью и их участием в индустриализации страны и подготовке новой генерации инженеров и техников.
\end{abstract}

Ключевые слова: С. Н. Ванков, мировоззрение, жизненное кредо, воспоминания, инженерно-техническая интеллигенция.

DOI: $10.35634 / 2412-9534-2019-29-4-698-704$

В январе 2018 г. исполнилось 160 лет со дня рождения генерал-майора Семёна (Симеона) Николаевича Ванкова (1858-1937 гг.) — одного из выдающихся представителей русской инженернотехнической интеллигенции конца XIX - первой трети XX вв. Выходец из семьи известного русофила и борца за независимость Болгарии Николая Ванкова, Семён Николаевич получил российское образование, служил в русской и болгарской армиях. В ходе сербско-болгарской войны 1885-1886 гг. майор Ванков как уполномоченный болгарского правительства встречался с русскими министрами военных и иностранных дел П. С. Ванновским и Н. К. Гирсом по вопросу приобретения Болгарией в России артиллерийского и стрелкового вооружения, а также для разъяснения внешнеполитической позиции болгарского правительства и возможного урегулирования болгарско-российских отношений, крайне осложнённых политикой князя Александра I Баттенберга.

С приходом к власти австрофилов Семён Николаевич, как один из руководителей русофильской партии, подвергся преследованиям: был арестован, бежал, пережил покушение на его жизнь. В России С. Н. Ванков поступил на службу и принял российское подданство. Служил он в крепостной артиллерии, руководил Ташкентским Окружным арсеналом, Хабаровским, Брянским арсеналами, был уполномоченным Главного артиллерийского управления (далее - ГАУ) по заготовлению снарядов по французскому образцу. После Октябрьской революции Семён Николаевич активно работал на руководящих должностях в системе ВСНХ и Госплана СССР, занимался наукой и преподаванием. На протяжении всей жизни его интересовали также общественные дела. Семён Николаевич был инициатором и создателем целого ряда различных общественных организаций. Так, инициировал создание и возглавил первое Болгарское техническое общество. В период пребывания на Дальнем Востоке занимался вопросами водо- и электроснабжения Хабаровска, был председателем Совета приамурского отдела Императорского русского географического общества, создал и возглавил работу ряда благотворительных организаций. Разнообразны были также и его научные интересы: ледники и холодильные установки, турбины, электротехника, металлургия и металлообработка, вопросы стандартизации производства и др.

Деятельность генерала Ванкова получила освещение сначала в болгарской литературе. Первым исследованием стала работа Л. Чакаловой, в значительной мере основанная на воспоминаниях Семёна Николаевича [9]. Однако в дальнейшем интерес к этой теме в Болгарии ослаб, так что в отечественной историографии жизнь и деятельность С. Н. Ванкова освещена скудно. Наиболее полная его биография представлена работой А. Я. Черняка, базирующейся на выявленных автором разнообразных архивных источниках [10]. В последние десятилетия фигура С. Н. Ванкова становится центральной в работах отечественных историков в связи с «Организацией Ванкова» ${ }^{1}$ [4].

\footnotetext{
${ }^{1}$ Общепринятое сокращённое название Организации уполномоченного ГАУ по заготовлению снарядов по французскому образцу генерал-майора С. Н. Ванкова.
} 
Пятьдесят из 59 девяти лет его активной практической, научной и общественной деятельности тесно связаны с историей нашей страны. Более того, профессиональные занятия С. Н. Ванкова на рубеже XIX-XX вв. пришлись на период становления и развития русской инженерно-технической интеллигенции как самостоятельной социально-профессиональной группы. На протяжении 1920 -х — первой половины 1930-х гг. в составе инженерно-технической интеллигенции СССР преобладали дореволюционные специалисты. Они не только участвовали в строительстве новой индустриальной базы страны (её инфраструктуры), но и обучали новую генерацию инженерно-технической интеллигенции. К концу 1930-х гг. в условиях советского общества произошёл существенный количественный рост этой группы с одновременным формированием её новых мировоззренческих установок. В этой связи большой интерес представляет мировоззрение генерала С. Н. Ванкова, внёсшего большой вклад в промышленное развитие Российской империи и в числе первых специалистов включившегося в разработку планов индустриального преобразования СССР. Преподавая в 1920-х - начале 1930-х гг. в различных технических и экономических вузах Москвы, он влиял на профессиональную подготовку новых инженернотехнических кадров и, в определённой степени, на их мировоззренческие установки.

В последнее время мировоззрение разных социальных групп и их отдельных представителей всё чаще становится предметом исследований отечественных историков [2;6]. Однако мировоззрение столь яркого и значительного представителя русской инженерно-технической интеллигенции, как С. Н. Ванков, пока не изучалось.

Деятельность человека и его мировоззрение находятся в определённой взаимосвязи. В современной философской литературе под мировоззрением понимают систему взглядов, ценностей, идеалов, убеждений, определяющих отношение человека к действительности, общее понимание им мира, его жизненную позицию, направление деятельности и образ жизни [1, с. $10 ; 3$, с. 8; 7, с. 375; 8, с. 334]. Оно всегда несёт в себе отпечаток индивидуально-личностных особенностей человека. На становление и развитие мировоззрения влияет индивидуальный опыт субъекта: и профессиональный, и заимствованные извне социокультурные представления, обусловленные его природной и социальной средой, с которой он взаимодействует.

Мировоззрение определяет направление деятельности и отношение к окружающей действительности. Анализ отношения С. Н. Ванкова к труду, мотивов, побуждающих его к той или иной деятельности, осознания им значимости выполняемой работы и собственных заслуг, отношения к восприятию его деятельности окружающими позволит выявить более общие его представления о месте и роли человека в мире. Отношение к окружающей реальности, в частности к своей Родине, народу, власти в некоторой степени раскрывает общественные, политические, экономические и нравственные взгляды С. Н. Ванкова.

Основной источник для данной работы - его воспоминания, хранящиеся в Научноисследовательском отделе рукописей Российской государственной библиотеки. Они представляют собой две рукописи (10 и 94 листа). Первая — «Воспоминания далёкой старины» - написана 10 марта 1910 г. в Хабаровске. Отсутствие какой-либо правки и общая завершённость текста говорят о том, что это скорее всего окончательный вариант воспоминаний. Вторая рукопись, представляет собой независимый от первой текст и названа «Мои воспоминания». Текст датирован 1929-1936 гг. и, очевидно, представляет собой черновой вариант, о чём свидетельствуют многочисленные авторские исправления, а также специально пропущенные чистые листы [5, ф. 218, карт. 303, д. 1, л. 20, 36-92, 116119, 126-127, 129-149, 181-188]. Оба текста содержат информацию о мотивах большинства из самых важных поступков в жизни автора, в т. ч. связанных с выбором профессии.

Интерес С. Н. Ванкова к техническим знаниям был естественен для юноши второй половины XIX в., когда возросло количество научных открытий, значительно ускорилось развитие техники и вместе с тем повысился престиж технического (в первую очередь инженерного) образования. В воспоминаниях С. Н. Ванкова косвенно подтверждается популярность технического образования у молодых людей того времени: «Громадное большинство учащихся нашей Николаевской реальной гимназии записалось в реальное училище, получившее наименование Николаевского Александровского Реального училища...» [5, ф. 218, карт. 303, д. 1, л. 5]. По окончании реального училища тяга к техническим знаниям и «желание принять участие в войне за освобождение родины...» вступили в некоторое противоречие и, по-видимому, С. Н. Ванков до конца колебался в выборе дальнейшего пути. Этим можно объяснить то, что он одновременно поступил в Петербургский Горный институт и во 2-е Константиновское военное училище, готовившее офицеров для пехоты. 
На окончательный выбор в пользу военного образования, по словам самого С. Н. Ванкова, повлияла славянская идея, «которая всюду и везде будировала... Идея освобождения родины Болгарии преобладала и покрывала все прочие помыслы и желания... Это было в то время, когда каждый болгарин горел желанием помочь всеми своими силами освобождению и организации своей вновь возродившейся родины... Какие розовые и прекрасные мечты обуревали нас всех, какие надежды нас окружали в то время...» [5, ф. 218, карт. 303, д. 1, л. 6-7об]. В итоге Семён Николаевич на время отказался от Горного института и поступил на военную рассчитывая принять участвовать в русско-турецкой войне 1877-1878 гг. за освобождение славян. В Горный институт Семён Николаевич вернулся позднее, в 1879-1880 гг., когда параллельно с обучением в Михайловской артиллерийской академии он вольнослушателем «проходил некоторые предметы-дисциплины по курсам Горного института». По словам самого С. Н. Ванкова, это углубило его знания и очень сильно помогло в дальнейшей его службе [5, ф. 218, карт. 303, д. 1, л. 9]. Безусловно, патриотизм был основополагающим мировоззренческим мотивом, определившим весь жизненный путь Ванкова. Корни патриотизма Семёна Николаевича были заложены его семьёй. Он воспитывался в атмосфере глубокой любви к Родине и превалирования общественного долга над личными интересами. Так как С. Н. Ванков закончил 2-е Константиновское училище по первому разряду, можно предположить, что учился он обстоятельно и серьёзно, готовясь принести реальную пользу своей стране. Об этом говорит и его дальнейшая квалифицированная военная служба в Болгарии.

Новый оттенок приобрело чувство патриотизма в последующей его жизненной позиции. В 1880-е гг. вновь обострилась борьба великих держав за влияние на Болгарию. Против России в регионе активно боролись Англия и Австро-Венгрия при поддержке Германии. Болгарское общество было разделено на две противоборствующие партии. Русофилы, составлявшие правительство страны, по численности существенно уступали австрофилам. Ситуация осложнялась тем, что князь Александр Баттенберг придерживался австро-германской ориентации, что привело к конфликту с Россией. В этих условиях в конце 1885 г. С. Н. Ванков в качестве уполномоченного болгарского правительства отправился в СанктПетербург. Целью его миссии было выяснение причин натянутых официальных отношений между Россией и Болгарией и разъяснение внешнеполитической позиции Болгарии. В Петербурге Семён Николаевич не только столкнулся с откровенно враждебным отношением к себе и русофильскому болгарскому правительству со стороны министра иностранных дел Н. К. Гирса, но и уверился в том, что «русское правительство решило добиться низвержения кн. Баттенберга... при помощи той или другой политической болгарской партии и в этом духе направляло свои шаги» $[5$, ф. 218 , карт. 303, д. 2, л. 5]. Таким образом, ответственность за государственный переворот в Болгарии и низвержение с престола князя А. Баттенберга 9 августа 1886 г. он возлагает на российское правительство. Однако, вопреки позиции российского правительства С. Н. Ванков делает всё возможное для победы русофильской партии в начавшейся в стране политической борьбе. После победы австрофильской группировки и начавшихся преследований сторонников П. Каравелова, в 1887 г. он тем не менее эмигрировал именно в Россию. Когда в 1895 г. большей части эмигрантов, находившихся в России, болгарским правительством была объявлена амнистия, С. Н. Ванкова она не коснулась. Российское правительство предложило ему либо перейти на постоянную службу в российскую армию, с условием не заниматься болгарской политикой, либо покинуть Россию. Семён Николаевич принял российское подданство и был вынужден дать русскому правительству обязательство «не заниматься болгарской политикой, не нарушать данное... слово» [5, ф. 218, карт. 303, д. 1, л. 2]. В связи с вышесказанным возникает вопрос не только о причине эмиграции С. Н. Ванкова в Россию, но и о причине принятия им российского подданства, которое стало своего рода констатацией окончательного превращения России для Семёна Николаевича во вторую Родину. Возможно, несмотря на то, что он считал себя и многих болгарских патриотов «жертвами русской политики и единственно этой политики» [5, ф. 218, карт. 303, д. 1, л. 10] её ошибки не смогли ослабить чувство его благодарности к России как освободительнице Болгарии. Тем более, что с Россией Семёна Николаевича уже многое связывало. Доказательством того, что Россия стала для С. Н. Ванкова второй родиной, является не только его добросовестная служба и направленная на благо страны и общества весьма успешная деятельность на различных постах, но и тот факт, что Семён Николаевич остался в России и после Октябрьской революции.

Принцип постоянного труда на благо Родины был основой жизненного кредо С. Н. Ванкова. Выражение любви к Родине через свой профессиональный труд, дающий приращение богатства и могущества родной стране, прослеживается на протяжении всей деятельности С. Н. Ванкова. Важными моти- 
вами деятельности для него были в первую очередь её целесообразность и общегосударственная польза. Это подтверждает его служба как начальника Туркестанского Окружного арсенала, находившегося в запустении из-за злоупотреблений его бывшего главы и всех служащих, преданных суду. При назначении С. Н. Ванкова на новую должность в апреле 1895 г. ему поставили задачу реорганизовать завод и ввести его в строй, что он сумел сделать уже к концу 1896 г. Семён Николаевич писал об этом в воспоминаниях: «Работать пришлось усиленно, так как, начиная с 1884 г., ещё при Емельянове [бывший начальник Туркестанского Окружного Арсенала. - E. T.] всё было запущено и лежало в складах Арсенала» [5, ф. 218, карт. 303, д. 1, л. 14]. Однако, «убедившись, что войска и артиллерия Туркестанского края не нуждаются в таком большом Арсенале», Ванков в конце 1897 г. выступил с инициативой его преобразования в ремонтную мастерскую при Туркестанском складе [5, ф. 218 , карт. 303 , д. 1, л. 14]. Таким образом, ради целесообразности и пользы общегосударственного дела он сознательно пошёл на понижение собственного статуса, что говорит об отсутствии среди его мотивов нездорового честолюбия и карьеризма. Об этом же позже свидетельствует и согласие С. Н. Ванкова занять должность начальника Хабаровской окружной артиллерийской мастерской.

Для автора воспоминаний характерна широта подхода к решению поставленных перед ним задач. Возникающие в процессе работы проблемы он рассматривал не с узкой позиции рядового инженера, а как организатор производства, заботившийся о перспективах его развития. Показательна в этом плане его работа руководителем «Организации Ванкова». Создавая свою Организацию, призванную решать проблему нехватки артиллерийских снарядов в период войны, Семён Николаевич уже при определении её структуры и принципов работы учитывал дальнейшее развитие входивших в неё предприятий в мирное послевоенное время. Эти черты С. Н. Ванкова особенно ярко проявились в его деятельности периода советской власти, описанной им во второй рукописи воспоминаний. В это время, занимая довольно высокие должности, он разрабатывал крупномасштабные проекты, предусматривавшие ликвидацию отставания отечественной промышленности, в частности, металлургии. Для этого было необходимо развивать производство стали, особенно её качественных сортов и цветных металлов, предварительно выявив их залежи и общие ресурсы. Поставленные задачи требовали комплексного и ускоренного решения, и С. Н. Ванков приступил к их реализации. Организованные при его руководстве и непосредственном участии Первое и Второе Всесоюзные совещания по цветным металлам имели большое значение для развития науки и техники в этой области. Совещания помогли объединить научно-технические кадры страны (включая геологов, горняков, металлургов), которые наметили программы не только развития цветной металлургии и металлообработки, но и геологических изысканий и увеличения добычи руд. Один из результатов этих совещаний - создание в апреле 1927 г. по инициативе С. Н. Ванкова Научно-технического совета по цветным металлам при ВСНХ СССР, чтобы консолидировать научно-технические и организационные усилия в области цветной металлургии и металлообработки. Возглавил этот совет С. Н. Ванков.

Помимо того, что производственная деятельность воспринималась С. Н. Ванковым как форма служения Родине, труд для него был естественным проявлением самой ипостаси человека, о чём он писал в воспоминаниях: «Вообще я не понимаю жизнь в безделии, и тунеядстве, и в удовольствиях. Жизнь - это труд для общества и государства, и в этом призвание человека, духовное удовлетворение и наслаждение. В труде и творчестве сказывается человек полностью и всецело, его склонности, его характер, воля и знания. Вообще труд облагораживает человека. И в этом глубокий смысл приучать [к] труду с малых лет ребят. Во всех своих работах я отдавался данному делу всецело; в этот момент я жил только для этого дела, искал наилучшего решения подлежащего рассмотрению вопроса и решительно, энергично работал в этом направлении, чем объясняю я успех, который меня всегда преследовал во всех моих делах и во всех обществах» [5, ф. 218, карт. 303, д. 1, л. 152].

Подтверждение сказанного - вся деятельность С. Н. Ванкова. В этом плане наиболее примечательно его пребывание в Хабаровске, поскольку именно здесь так ярко проявились особенности личности С. Н. Ванкова, так полно раскрылась его неуёмная энергия. О Дальнем Востоке он с восторгом пишет: «Жизнь Дальнего Востока была оригинальна, т. к. она не напоминала скучную жизнь городов Европ[ейской] России, где развитие шло очень медленно и чаще всего неправильно, а скорее дальневосточная жизнь несколько напоминала американскую жизнь, жизнь живую, и созидательную, творческую. Правда, материальные средства ограничивали несколько наш размах, наше творчество, но организованные общества помогали развитию края и своеобразности его жизни» $[5, \phi .218$, карт. 303 , д. 1 , л. 109]. Стремление к созданию чего-то нового можно охарактеризовать как склонность к предпринима- 
тельству. В период своей службы в Хабаровске С. Н. Ванков не только энергично развивал деятельность вверенной ему Хабаровской Окружной мастерской, но и активно способствовал развитию городского хозяйства Хабаровска, что подтверждается историей строительства им в городе водопровода и электростанции. При сооружении водопровода С. Н. Ванков был инициатором и самого строительства, и разработчиком его первоначального проекта. Воплощение идеи было предоставлено хабаровскому городскому инженеру. Полностью на себя С. Н. Ванков взял строительство в городе электростанции. Идея её сооружения родилась ещё во время Русско-японской войны, когда город испытывал перебои с освещением. Первоначально предполагалось провести освещение лишь военного собрания, домов командующего войсками и начальника края. Однако главнокомандующий русскими войсками на Дальнем Востоке генерал А. Н. Куропаткин отказал в единовременном ассигновании на это дело 17000 руб. По словам С. Н. Ванкова, отказ послужил для него «толчком к устройству городского освещения во всём Хабаровске» и «вызвал... желание и стремление доказать, что можно обойтись без казённых ассигнований для целей освещения» $[5$, ф. 218, карт. 303 , д. 1, д. 154]. С. Н. Ванкову несвойственно было отступать перед трудностями. Более того, препятствия только активизировали его деятельность, порождали стремление преодолеть их. Осенью 1905 г. С. Н. Ванков обратился к членам городской управы и группе хабаровских купцов с предложением образовать «Товарищество на вере по электрическому освещению города» с возможным последующим преобразованием этого товарищества в акционерное общество. В течение месяца Товарищество было создано с двумя ответственными учредителями в лице С. Н. Ванкова и городской управы. Семён Николаевич должен был составить проект и смету, а также осуществить строительство электростанции. Городская администрация обязалась бесплатно предоставить Товариществу под строительство землю на берегу Амура [5, ф. 218, карт. 303, д. 1, л. 154].

При сооружении электростанции С. Н. Ванков проявил себя как рачительный хозяин и человек слова. Всё строительство проходило в режиме жёсткой экономии средств. В то же время стремление к удешевлению строительства было реализовано так, чтобы не страдало качество производимых работ. Для возведения несложной кирпичной кладки корпусов электростанции С. Н. Ванковым были наняты китайские рабочие. При сооружении трубы станции Семён Николаевич отказался от услуг немецкой и японской строительных компаний, посчитав их расценки довольно дорогими, и прибег к труду русских солдат, возвращавшихся из Маньчжурии, среди которых нашлись и каменщики $[5$, ф. 218, карт. 303 , д. 1, л. 155-156]. С. Н. Ванков был связан жёстким графиком работ, поскольку «обещал Городской Думе и Управе дать электрическое освещение 1 ноября» 1906 г. [5, ф. 218, карт. 303, д. 1, л. 112]. Несмотря на трудности с возведением кирпичной трубы электростанции, отправкой фирмойизготовителем заказанного в Германии электрооборудования не в Хабаровск, а в Харбин, что выяснилось в последний момент, он выполнил своё обещание и пустил электростанцию в назначенный срок.

В Хабаровске проявилось и внимание С. Н. Ванкова к проблемам, лишь косвенно относившимся к его инженерной деятельности, но характеризовавшим его гражданскую позицию. Начавшаяся в 1906 г. столыпинская аграрная реформа увеличила поток крестьян-переселенцев на Дальний Восток. В этих обстоятельствах С. Н. Ванков особое внимание уделил переселенческой политике. Проанализировав проблемы переселенцев, он пришёл к выводу, что «необходимо было приучить крестьянпереселенцев к кустарному труду, который мог бы дать им зимой приработок, что облегчило бы их жизнь» [5, ф. 218, карт. 303, д. 1, л. 103]. В 1910 г. Семён Николаевич взялся за организацию Центрального Дальневосточного кустарного комитета в Хабаровске. Комитет занимался обучением крестьян различным промыслам и обеспечением заказов на их продукцию. Итоги этой работы демонстрировались в 1913 г. на Промышленно-кустарной выставке Приамурского края.

Несмотря на всю широту, масштаб деятельности С. Н. Ванкова на Дальнем Востоке не так значителен в сравнении с его работой как уполномоченного ГАУ. Особенно ярко предпринимательский и организаторский таланты Семёна Николаевича проявились при формировании структуры организации, развитии кооперации как определённой формы обобществления производства, учёбе кадров всех уровней и повышении их квалификации, при использовании новых технологических идей для преодоления узких мест в промышленной базе предприятий и устранении дефицита высококачественных материалов. «Организация Ванкова» в некотором смысле представляла собой прообраз будущих советских научно-производственных объединений.

В общественной позиции С. Н. Ванкова отчётливо прослеживается демократическое начало. Неприятие сословной ограниченности, замкнутости в рамках незначительных внутренних интересов и нежелания замечать насущные проблемы всего общества отчётливо выражены в оценке им общест- 
венной жизни Туркестана. С. Н. Ванков пишет: «...жизнь в Ташкенте не представляла в те времена ничего интересного. Общество жило своими мелкими ежедневными сплетнями и дрязгами и ничем особенно не интересовалось. В военном и общественном собраниях крайне редко делались доклады на общественные и научные темы. Главным образом занимались в этих собраниях игрой в карты с раннего вечера до поздней ночи. Устраивались также в этих собраниях танцевальные вечера и иногда (изредка) спектакли любителей. Я крайне редко бывал на этих вечерах ввиду большой ежедневной работы до поздней ночи в Арсенале» [5, ф. 218, карт. 303, д. 1, л. 17]. В определённой мере такой застой общественной жизни объясняется особенностями самого края, общество которого было чётко разделено по национальному, религиозному и сословному признакам. С одной стороны, оно было представлено коренным мусульманским населением, жизненный уклад которого при вхождении в состав Российской империи практически не изменился, а с другой - относительно немногочисленными представителями русской администрации и переселенцами.

Дальний Восток, несмотря на то, что он, как и Туркестан, являлся окраиной России и был заселён слабее, совершенно отличался от последнего большим демократизмом в общественной атмосфеpe, отсутствием косности, что позволило С. Н. Ванкову начать в крае активную общественную работу. Его повествование о Дальнем Востоке начинается с того, как много перспектив увидел он в развитии этого края: «по прибытии на Дальний восток и осмотревшись кругом, я понял, как много там работы открывается для человека культурного, желающего принести пользу своей родине в смысле культурного развития её» $[5$, ф. 218, карт. 303, д. 1 , л. 93]. И далее продолжает: «Жизнь на Дальнем Востоке была оригинальна на хорошее. Оригинальна по необходимости принимать участие во всех видах общественности... Была возможность устраивать ежедневные заседания того или другого общества и таким образом сделать жизнь хорошей и полезной для жителей городов Приамурья, т. к. по примеру столицы Приамурья - гор. Хабаровска и все другие города стали постепенно организовывать подобную общественную культурную жизнь у себя. Способствуя тем самым развитию и постепенному подъёму культурности края» [5, ф. 218, карт. 303 , д. 1, л. 109]. Широкий охват различных вопросов, которых касалась общественная деятельность С. Н. Ванкова, в первую очередь говорит о его стремлении быть полезным в тех областях жизни Дальневосточного края, где своей деятельностью он принесёт пользу широким слоям населения. Это подтверждают также его участие в постройке хабаровского водопровода, организация и строительство им городской электростанции, создание и работа в краевом Кустарном комитете и «Обществе вспомоществования нуждающимся учащимся учебных заведений Министерства народного просвещения».

Таким образом, ключевым поведенческим мотивом и основой мировоззрения С. Н. Ванкова был патриотизм, выражавшийся через идею постоянного труда на благо общества. Именно кропотливый труд, по мнению Семёна Николаевича, был залогом всех его достижений. Производственная деятельность воспринималась им как необходимая форма служения Родине. Важными её аспектами были целесообразность и общегосударственная польза. Для С. Н. Ванкова были характерны широта подхода к решению поставленных задач, честность, инициативность, смелость, стремление идти к поставленной цели зачастую не благодаря, а вопреки обстоятельствам. Во взглядах на общество прослеживается демократическое начало, проявлявшееся в остром неприятии сословной ограниченности и замкнутости на узкосоциальных интересах.

\section{СПИСОК ИСТОЧНИКОВ И ЛИТЕРАТУРЫ}

1. Белов А. П. Мировоззрение и образ жизни: социально-философские проблемы. Саратов: Поволжская академия гос. службы им. П. А. Столыпина, 2006. 192 с.

2. Васильева Е. В. О мировоззрении дальневосточных учёных первой половины XX века // Вестн. Дальневосточного отделения Российской академии наук. 2005. №5. С. 98-118.

3. Введение в философию: учеб. пособие для вузов. М.: Республика, 2003. 623 с.

4. Орлов А. В. Организация Уполномоченного Главного Артиллерийского управления генерал-майора С. Н. Ванкова: сделать невозможное // Воен.-ист. журн. 2018. № 1. С. 53-59.

5. Российская государственная библиотека. Научно-исследовательский отдел рукописей (РГБ НИОР)

6. Семёнова Е. Ю. Мировоззрение городского населения Поволжья в годы Первой мировой войны (1914 начало 1918 гг.): социокультурный, экономический, политический аспекты. Самара: АНО «Издательство СНЦ РАН», 2012. $888 \mathrm{c}$.

7. Спиркин А. Г. Мировоззрение // Философский энциклопедический словарь. М.: Советская энциклопедия, 1983. C. $375-376$.

8. Юдин Б. Г. Мировоззрение // Философский словарь. М.: Республика, 2001. С. 334. 
9. Чакалова Л. Генерал Симеон Ванков. София, 1973. 105 с.

10. Черняк А. Я. Семён Николаевич Ванков, 1858-1937. М.: Наука, 1984. 175 с.

Поступила в редакцию 24.12.2018

Тронина Елена Владимировна, магистрант кафедры истории России

ФБГОУ ВО «Удмуртский государственный университет»

426034, Россия, г. Ижевск, Университетская, 1 (корп. 2)

E-mail: source1817@gmail.com

\section{E.V. Tronina}

SOME ASPECTS OF S. VANKOV'S WORLDVIEW (ON THE MATERIALS OF HIS MEMOIRS)

DOI: $10.35634 / 2412-9534-2019-29-4-698-704$

The article examines S.N. Vankov's worldview and life creed based on his memoirs, revealing the motivation of his professional and social activities, his attitude to work, his concepts of homeland, power and society. Throughout the lifetime of memoirs' author, the consistency of his life principles and beliefs is traced, regardless of the change of political power in Russia. The paper focuses on the worldview of the engineering and technical intelligentsia of the late 19th and first third of the 20th century, the brightest representatives of which include Semyon Nikolaevich Vankov. The issue acquires particular relevance in the context of cooperation between the so called old bourgeois specialists and Soviet authorities, and their participation in the industrialization of the country and the tutoring of a new generation of engineers and technical specialists.

Keywords: S. N. Vankov, worldview, life creed, memoirs, engineering and technical intelligentsia.

\section{REFERENCES}

1. Belov A. P. Mirovozzreniye i obraz zhizni: sotsial'no-filosofskiye problemy [Worldview and life style: social and philosophical issues]. Saratov, Stolypin Volga Region Academy of State service Press, 2006, 192 p. (In Russian).

2. Vasil'yeva E. V. O mirovozzrenii dal'nevostochnykh uchenykh pervoy poloviny XX veka [On the worldview of Far Eastern scholars of the early 20th century]. Vestnik Dal'nevostochnogo otdeleniya Rossiyskoy akademii nauk [Bulletin of the Far Eastern Branch of the Russian Academy of Sciences], 2005, no. 5, pp. 98-118. (In Russian).

3. Vvedeniye v filosofiyu: ucheb. posobiye dlya vuzov [Introduction to Philosophy: a textbook for Universities]. Moscow, Republic Publ., 2003, 623 p. (In Russian).

4. Orlov A. V. Organizatsiya Upolnomochennogo Glavnogo Artilleriyskogo upravleniya general-mayora S. N. Vankova: sdelat' nevozmozhnoye [The organization of the Authorized Main Artillery Directorate by Major-General S. N. Vankov: to do the impossible]. Voyenno-istoricheskiy zhurnal [Military history magazine], 2018, no. 1, pp. 53-59. (In Russian).

5. Rossiyskaya gosudarstvennaya biblioteka. Nauchno-issledovatel'skiy otdel rukopisey (RGB NIOR) [Russian State Library. Academic research department of manuscripts].

6. Semenova E. Y. Mirovozzreniye gorodskogo naseleniya Povolzh'ya v gody Pervoy mirovoy voyny (1914 — nachalo 1918 gg.): sotsiokul'turnyy, ekonomicheskiy, politicheskiy aspekty [Worldview of the urban population of the Volga region during the First World War (1914 — early 1918): socio-cultural, economic, political aspects]. Samara, Ed. of the Samara Research Center of the Russian Academy of Sciences”, 2012, 888 p. (In Russian).

7. Spirkin A. G. Mirovozzreniye [Worldview]. Filosofskiy entsiklopedicheskiy slovar' [Philosophical Encyclopedic Dictionary]. Moscow, Soviet Encyclopedia Publ., 1983, pp. 375-376. (In Russian).

8. Yudin B. G. Mirovozzreniye [Worldview]. Filosofskiy slovar, [Philosophical dictionary]. Moscow, Republic Publ., 2001, p. 334. (In Russian).

9. Chakalova L. General Simeon Vankov [General Simeon Vankov]. Sofia, 1973, 105 p. (In Bulgarian).

10. Chernyak A. Ya. Semen Nikolayevich Vankov, 1858-1937. Moscow, Nauka Publ., 1984, 175 p. (In Russian).

Received 24.12.2018

Tronina E.V., undergraduate student of the Department of Russian history

Udmurt State University

Universitetskaya st., 1/2, Izhevsk, Russia, 426034

E-mail: source1817@gmail.com 